\title{
Phenomenological characteristics and explanations of unusual perceptual experiences, thoughts and beliefs in a population sample of early adolescents
}

\author{
H. Coughlan ${ }^{1 * *}$ (D) , C. Healy ${ }^{1}$ (D) N. Humphries ${ }^{2}$, M. Clarke ${ }^{1,3}$, I. Kelleher ${ }^{1,4}$ and M. Cannon ${ }^{1,5}$ \\ ${ }^{1}$ Department of Psychiatry, Royal College of Surgeons in Ireland \\ ${ }^{2}$ Royal College of Physicians of Ireland \\ ${ }^{3}$ Department of Psychology, Royal College of Surgeons in Ireland \\ ${ }^{4}$ Department of Psychiatry, Trinity College Dublin \\ ${ }^{5}$ Department of Psychiatry, Beaumont Hospital Dublin, Ireland
}

Objectives: Often referred to as psychotic experiences, unusual perceptual experiences, thoughts and beliefs (UPTBs) are not uncommon in youth populations. Phenomenological studies of these experiences are lacking. This study aimed to (1) describe the phenomenological characteristics of UPTBs in a sample of young adolescents and (2) explore how young people made sense of those experiences.

Methods: Participants were 53 young people aged 11-13 years from a population-based study of mental health. All met criteria for UPTBs following clinical interviews as part of the study. Documentary data on UPTBs in the form of transcribed notes, recorded during clinical interviews, were analysed using content analysis. Data on UPTBs were coded, organised into categorical themes and quantified using descriptive statistics. Qualitative themes on how participants made sense of their experiences were identified.

Results: Participants reported UPTBs across four domains: auditory verbal, auditory non-verbal, non-auditory perceptual experiences and unusual thoughts and beliefs. UPTBs were phenomenologically rich and diverse. Young people sought to make sense of their experiences in multiple ways: normalising them, externalising them by attributing them to paranormal entities and distancing them from psychiatric explanations. Uncertainty about the source of UPTBs was identified as a superordinate theme.

Conclusion: Findings from this study offer new insights into the phenomenological qualities and characteristics of UPTBs in young adolescents. They also reveal that early adolescents may not make sense of their experiences within a psychiatric framework. These findings highlight the need to develop a more phenomenologically sensitive and nuanced approach to studying UPTBs in young people.

Received 24 March 2020; Revised 17 April 2020; Accepted 20 April 2020; First published online 27 May 2020

Key words: Anthropology, delusions, hallucinations, phenomenology, qualitative, youth.

\section{Introduction}

Typically referred to as psychotic or psychotic-like experiences, unusual perceptual experiences, thoughts and beliefs (UPTBs) refer to hallucinatory and delusionlike experiences that occur in the absence of psychotic disorder. Interest in the phenomenology of UPTBs in young people is not new. In one 1908 paper, Adolf Meyer described children who were repressed, whose minds were turned inward and who experienced a depth of thought. Meyer reported these as early markers of 'dementia praecox', the term coined by Kraeplin in 1896 for what is now known as schizophrenia

*Address for correspondence: Helen Coughlan, Clinical Research Fellow, Department of Psychiatry, Royal College of Surgeons in Ireland, RCSI Education and Research Centre, Beaumont Hospital, Dublin 9, Ireland.

(Email: helencoughlan@rcsi.ie)
(Meyer, 1908). In making an early 20th-century case for early intervention, he wrote:

We realize that there are many children who show the traits mentioned, and possibly we know that some of our friends manifested traits like seclusiveness, occasional day-dreaming, and discrepancies between thought and action. It must be admitted that these traits alone are not sufficient indications of inevitable failure. On the other hand, we insist that those who can take and heed a warning will be saved from danger by a timely recognition of what risks there are. A knowledge of the mode of development of some of the graver mental disorders must help us to discriminate those traits of character that should serve as warnings to be heeded. (Meyer, 1908: 95)

Forty years later, Despert (1948) reported evidence of UPTBs in three groups of children, each with differing 
levels of psychopathology. Among preschool children without any psychopathology, she found limited evidence of 'pseudohallucinations', particularly in children with anxiety. She also found evidence of hallucinatory and delusional phenomena in children with behavioural and neurotic difficulties, and in children with psychosis. However, qualitative differences were evident in the phenomenology of UPTBs in children with different psychopathological profiles. In children with behavioural and neurotic difficulties, UPTBs were singular and simplistic; whereas in children with psychosis, UPTBs were akin to those reported by adults with psychotic disorders.

More recently, epidemiological studies have shown that an estimated $5 \%$ of people will experience UPTBs, about $80 \%$ of whom will do so only transiently (Van Os et al. 2009). Higher rates have been found among children and adolescents. Evidence from one systematic review and meta-analysis found that an estimated $17 \%$ of 9- to 12-year-olds from the general population will experience these phenomena (Kelleher et al. 2012a), and recent findings from a large longitudinal study in the UK found that the incidence of UPTBs peaked in late adolescence (Sullivan et al. 2020). Available evidence also suggests that UPTBs may be a risk marker for psychopathological and functioning difficulties (Yung et al. 2005; Kelleher et al. 2012b; Stochl et al. 2015; Calkins et al. 2017; Healy et al. 2018a; Healy et al. 2018b; Rimvall et al. 2018). However, that risk is neither absolute nor weighted equally among young people who report these experiences (Beavan et al. 2011, Coughlan et al. 2019).

It has been proposed that UPTBs should be conceptualised as existing on a continuum of human experience, from that which is considered 'normal' to that which is deemed pathological (Bentall, 2004, Van Os et al. 2009). However, in their systematic review of auditory verbal hallucinations (AVHs), Upthegrove et al. (2016) noted that insufficient evidence exists to reliably draw any conclusions about whether or not AVHs lie on the same continuum for healthy individuals and those with psychosis. Furthermore, UPTBs encapsulate an array of heterogeneous experiences that involve multiple sensory modalities (Oyebode, 2015, Pienkos et al. 2019) and a wide range of cognitive, emotional and unconscious processes (Garety et al. 2001; Longden et al. 2012; Martindale \& Summers, 2013; Taylor \& Harper, 2016; Pugh et al. 2018). Additionally, the breadth of thoughts, beliefs and perceptions reported may be experienced with varying levels of intensity, complexity and impact (Larøi et al. 2014).

From an anthropological perspective, UPTBs cannot be considered outside of the cultural context within which they are experienced (Larsen, 2004; Al-Issa, 2018; Pienkos et al. 2019). Culture is central to understanding how meaning is ascribed to these experiences and how they are personally, socially, medically or spiritually constructed (Harland et al. 2004; Rabeyron \& Watt, 2010; Corstens et al. 2014; Larøi et al. 2014; Al-Issa, 2018). From a sociocultural perspective, the language used to describe these experiences is also relevant, particularly in the field of mental health where psychiatric labels and terminology have meaning and can result in stigma (Corrigan \& Kleinlein, 2005). Thus, on account of their linguistic association with psychotic disorders, terms such as psychotic experiences and psychotic-like experiences have the potential to be both ambiguous and stigmatising. Though not without its own limitations, the term UPTBs adopted in this study goes some way towards offering a less stigmatising descriptor to capture these experiences and beliefs.

In light of the complexity and diversity of UPTBs, it has been argued that a deeper understanding of their phenomenology may contribute to a more nuanced understanding of their meaning and significance (Brendel, 2006; Larøi et al. 2012; Humpston, 2014; McCarthy-Jones et al. 2014; Upthegrove et al. 2016). However, in spite of a recent surge of interest in UPTBs, phenomenological data on the nature of these experiences in youth populations are notably lacking. What is more, research to date has emphasised voice hearing over other types of UPTBs, with few programmes of research exploring the full breadth of hallucinatory or delusion-like experiences in young people. The aims of the current study were to (a) describe the phenomenology of UPTBs in a non-psychotic sample of young adolescents who reported these experiences and (b) explore young people's explanations for these experiences. The study was undertaken within a phenomenological framework, which gives primacy to individuals' subjective interpretations of their lived experiences (Kvale, 1996; Creswell, 2012). Phenomenology can also be applied descriptively to identify and categorise subjectively experienced phenomena (Oyebode, 2015; Upthegrove et al. 2016).

\section{Methods}

\section{Study participants}

Participants were 53 young people from the Adolescent Brain Development (ABD) study. ABD is a longitudinal study that has been examining psychopathology, UPTBs, neurocognition and brain development in a population sample of Irish youth since 2007. Full details about the study have previously been reported (Kelleher et al. 2012c, Coughlan et al. 2014). Briefly, recruitment for the study involved an initial survey of 1131 adolescents aged 11-13 years from a representative sample of primary schools in North Dublin and 
environs using the SDQ (Strengths and Difficulties Questionnaire) (Goodman, 1997) and the Adolescent Psychotic Symptoms Screener (Kelleher et al. 2011). Of those, 211 attended for detailed clinical interview and cognitive assessment.

During clinical interviews, psychopathology was assessed using the Schedule for Affective Disorders and Schizophrenia (K-SADS-PL), a validated clinical assessment tool for examining Axis I mental disorders in children and adolescents according to the Diagnostic and Statistical Manual of Mental Disorders, 4th Edition (Kaufman et al. 1997). As part of the ABD study protocol, the psychosis section of the K-SADS-PL was supplemented with additional questions on young people's experiences of UPTBs over the course of their lifetime. These included questions about young people's attributions for their UPTB experiences. All participants were also asked to rate their level of distress in response to their UPTBs on a scale of 0 to $10(0=$ no distress, 10 $=$ very distressed). During clinical interviews, members of the study team documented details of all responses to questions about UPTBs using contemporaneous handwritten notes. All handwritten notes on participant responses were then transcribed verbatim and stored as string data in the ABD study file. To determine rates of UPTBs, these string data were reviewed by two psychiatrists and one psychologist on the study team. Firstly, each reviewer rated all string data independently (see Supplement for details of criteria used). Once independent rating was complete, all three reviewers met for a consensus meeting to discuss and finalise the ratings (Kelleher et al. 2012c). Those who met criteria for UPTBs made up the sample for this study.

\section{Study design}

Documented qualitative data on reported UPTBs were analysed for the 53 respondents who met the UPTB criteria following clinical interviews. Data were in the form of the transcribed notes that had been documented contemporaneously by study interviewers during clinical interviews. Content analysis was used to conduct the analysis. It was chosen because it can be applied to the analysis of all forms of recorded communication (Mayring, 2004) with the flexibility to present findings both quantitatively and qualitatively (Krippendorff, 2004). It is also considered a suitable method for descriptive studies that aim to 'identify and categorize all instances of a particular phenomenon' (Hsieh \& Shannon, 2005). Analyses were conducted by the first author.

After reading and re-reading the data, an initial coding frame was developed (Assarroudi et al. 2018). This descriptive phenomenological coding frame was informed by details of hallucinatory and delusional experiences as described in Oyebode's Textbook of Descriptive Psychopathology (Oyebode, 2015). It was organised around four categorical domains: (1) auditory verbal phenomena (hearing voices and audible thoughts), (2) auditory non-verbal phenomena (hearing non-verbal sounds), (3) non-auditory perceptual phenomena (visual, tactile and olfactory experiences), and (4) unusual thoughts and beliefs (delusional, delusion-like, paranoid and persecutory thoughts and beliefs). Collectively, domains 1-3 were concerned with unusual perceptual experiences (UPEs). Domain 4 was concerned with unusual thought content and beliefs.

As coding progressed, new descriptive categories were added to capture any phenomenological characteristics of UPTBs documented within the data that were not part of the original coding frame. These included descriptive codes for the characteristics of voice hearing reported. In line with the study aims and the documentary data used for analysis, phenomenological codes reflected semantic themes (i.e. what was explicitly documented) within the data (Braun \& Clarke, 2006). For all categories and domains of experience, binary (yes/no) coding was applied to indicate the presence or absence of the experience or characteristic. Once coding was complete, the binary codes were used to quantify the phenomenological characteristics of UPTBs using descriptive statistics. Although illusions were frequently reported by participants, as they are not considered to reflect any form of perceptual abnormality (Oyebode, 2015), they were excluded from the analysis.

In addition to the descriptive coding frame, inductive coding (Hsieh \& Shannon, 2005; Braun \& Clarke, 2006) was used to analyse how participants explained or made sense of their UPTBs. New codes were created based on both semantic and latent themes identified in the data. These were then reviewed and organised into broader descriptive themes (Braun \& Clarke, 2006). In this article, these thematic findings are presented qualitatively. Illustrative examples provided are exact and unedited extracts from the contemporaneous notes as documented by the study interviewers. Due to the large number of participants, each participant is identified by a simple gender/number code (e.g. F1 refers to Female 1, M5 refers to Male 5, etc.).

\section{Results}

\section{Quantitative findings on the phenomenological characteristics of UPTBs}

The sample was made up of 53 individuals aged $11-13$ years $($ mean $=11.5$ years, S.D. $=0.65), 60.4 \%$ of whom was male and $39.6 \%$ of whom were female. 


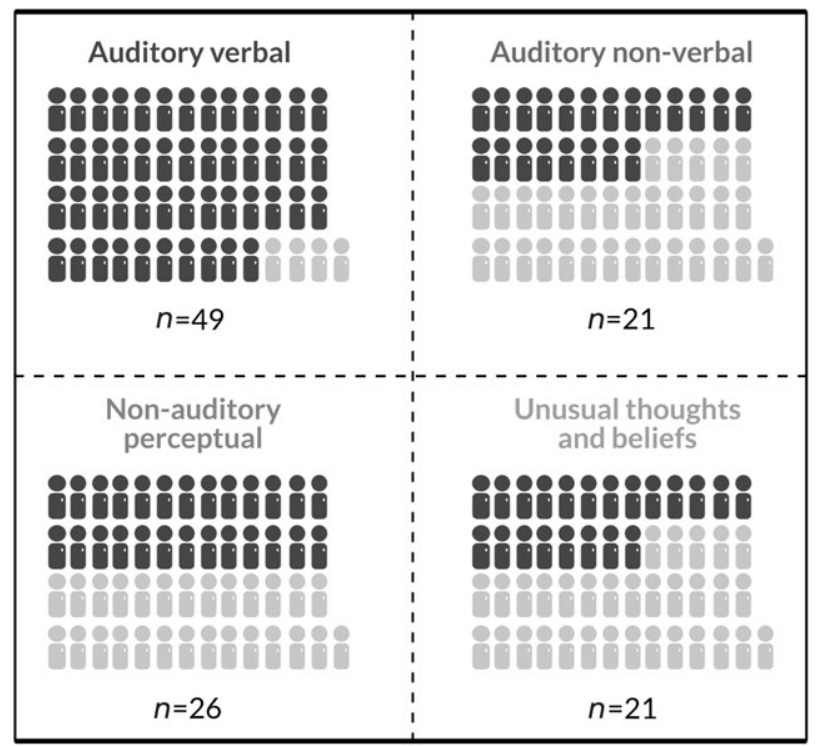

Figure 1. Number who reported unusual perceptual experiences, thoughts and beliefs within each phenomenological domain $(\mathrm{N}=53)$.

Across the sample, participants experienced UPTBs across all four phenomenological domains. Almost all participants $(n=49)$ reported auditory verbal phenomena and over one third of the individuals reported experiences within each of the other three domains (see Figure 1).

A majority of participants reported experiences in one $(n=17)$ or two $(n=17)$ domains only. Ten reported experiences across three domains and the remaining nine individuals reported experiences across all four domains. Full details of the phenomenological categories and domains of UPTBs are presented in Table 1.

\section{Quantitative findings on the phenomenological characteristics of voice hearing}

Forty-eight participants reported hearing voices and this was the only phenomenon reported by 14 individuals in the sample. Participants who heard voices reported a diverse range of voice-hearing characteristics related to their frequency, source, quality, content and tone. Most participants heard voices infrequently, with about one third reporting voice hearing on only one or a few occasions. It was more common for the voice-hearing sample to report multiple and adult voices than singular or child voices. Many participants described indistinct voices, with very few reporting commanding or commenting voices. However, some young people reported voices cautioning them against doing things that may cause them harm, with others reporting voices that suggested rather than commanded them to do things.
Further details on the phenomenological characteristics of voice hearing are contained in Table 2.

\section{Qualitative findings on young people's explanatory and sense-making framezorks}

Three sub-themes, normalising, externalising and distancing, and one superordinate theme, uncertainty, were identified in documented reports of how young people tried to make sense of their UPTBs. While sub-themes are presented separately, they were not mutually exclusive. As reflected in the superordinate theme of uncertainty, in many cases there was a dynamic interplay between explanatory sub-themes.

\section{Sub-theme 1: Normalising}

Normalising was when participants rationalised their experiences using a normative intrapersonal cognitive frame of reference. Examples included young people explaining their perceptual experiences as tricks of the mind, figments of the imagination or as memories. Normalising was the most common way young people interpreted or explained their experiences. Almost three quarters of participants used normalising to explain at least one of the experiences they reported. Two-in-five offered normalising as the only explanation for their experiences.

The most common rationalisation was that perceptual experiences were simply an artefact of participants' own imaginations. For some young people, this process of rationalising their experiences was evident even 
Table 1. Phenomenological characteristics of unusual perceptual experiences, thoughts and beliefs ( $n=53)$

\begin{tabular}{|c|c|c|}
\hline Phenomenological domains and categories & $n$ & $\%$ \\
\hline Domain 1: auditory verbal experiences & 49 & 92.5 \\
\hline Hearing voices & 48 & 90.6 \\
\hline Audible thoughts (hearing own thoughts aloud) & 9 & 17.0 \\
\hline Hearing voices and audible thoughts & 8 & 15.1 \\
\hline Domain 2: Non-verbal auditory experiences & 21 & 39.6 \\
\hline Music & 10 & 18.9 \\
\hline Other sounds* & 8 & 15.1 \\
\hline Banging sounds/sound of items falling to the ground & 5 & 9.4 \\
\hline Footsteps & 3 & 5.7 \\
\hline Multiple non-verbal auditory experiences & 5 & 9.4 \\
\hline Experiences only occurred hypnagogically or hypnopompically & 3 & 5.7 \\
\hline Domain 3: non-auditory perceptual experiences & 26 & 49.1 \\
\hline Visual perceptual experiences & 20 & 37.7 \\
\hline Human figures or faces & 13 & 24.5 \\
\hline Non-human entities (the Devil, ghosts, aliens) & 12 & 22.6 \\
\hline Other visual & 8 & 15.1 \\
\hline Multiple visual perceptual experiences & 11 & 20.8 \\
\hline Tactile experiences & 9 & 17.0 \\
\hline Feeling of being touched & 9 & 17.0 \\
\hline $\begin{array}{l}\text { Other tactile experience (crawling on skin, being } \\
\text { breathed on) }\end{array}$ & 2 & 3.8 \\
\hline Olfactory experiences & 5 & 9.4 \\
\hline Multiple non-auditory perceptual experiences & 6 & 11.3 \\
\hline Domain 4: unusual thoughts and beliefs & 21 & 39.6 \\
\hline External forces controlling self or others & 8 & 15.1 \\
\hline Belief in special powers & 5 & 9.4 \\
\hline Paranoid or persecutory beliefs & 5 & 9.4 \\
\hline Mind reading (others having this ability) & 5 & 9.4 \\
\hline Thought insertion & 4 & 7.5 \\
\hline Ideas of reference & 3 & 5.7 \\
\hline Grandiose beliefs & 3 & 5.7 \\
\hline Mind reading (self having this ability) & 2 & 3.8 \\
\hline Thought broadcasting & 1 & 1.9 \\
\hline Thought withdrawal & 1 & 1.9 \\
\hline Multiple unusual thoughts and beliefs & 8 & 15.1 \\
\hline \multicolumn{3}{|l|}{ Number of domains } \\
\hline 1 Domain only & 17 & 32.1 \\
\hline Auditory verbal domain only** & 14 & 26.4 \\
\hline Elementary auditory domain only & 1 & 1.9 \\
\hline Non-auditory perceptual domain only & 1 & 1.9 \\
\hline Unusual thoughts and beliefs domain only & 1 & 1.9 \\
\hline 2 Domains & 17 & 32.1 \\
\hline 3 Domains & 10 & 18.9 \\
\hline 4 Domains & 9 & 17.0 \\
\hline
\end{tabular}

*Other sounds include sounds of animals, ringing phones, shields and war, sounds of ghosts/spirits, chains rattling ** All individuals in this category only heard voices

when the phenomena they experienced were clear, vivid perceptions and a source of distress.

A couple of weeks ago she was home alone and could hear a loud man's voice (a kind of screaming sound rather than actual words), and also a little girl's voice, sounded like low pitch muttering, thought she saw footsteps under the door as well but didn't actually see anyone, this incident lasted for about 1 hour, she phoned her friend and asked 
Table 2. Phenomenological characteristics of voice hearing $(n=48)$

\begin{tabular}{|c|c|c|}
\hline Characteristics of voice hearing & $n$ & $\%^{1}$ \\
\hline \multicolumn{3}{|l|}{ Number of voices heard } \\
\hline Hearing a single voice only & 19 & 39.6 \\
\hline Hearing multiple voices & 27 & 56.3 \\
\hline \multicolumn{3}{|l|}{ Type and clarity of voices } \\
\hline Voices sound similar to human voices & 41 & 85.4 \\
\hline Indistinct or mumbling voices & 20 & 41.7 \\
\hline Voices speak in sentences & 19 & 39.6 \\
\hline Screeching or screaming voices & 7 & 14.6 \\
\hline Voice singing & 1 & 2.1 \\
\hline \multicolumn{3}{|l|}{ Content of voices } \\
\hline Hearing name being called aloud & 14 & 29.2 \\
\hline Conversing voices & 11 & 22.4 \\
\hline Commanding voice & 4 & 8.3 \\
\hline Cautioning voice & 2 & 4.1 \\
\hline Suggesting voice & 4 & 8.3 \\
\hline Commenting voice & 1 & 2.1 \\
\hline Malevolent content & 3 & 6.3 \\
\hline \multicolumn{3}{|l|}{ Relationship of voices to the individual } \\
\hline Voices of people not known to the individual & 32 & 66.7 \\
\hline Voices of people known to the individual & 15 & 31.3 \\
\hline \multicolumn{3}{|l|}{ Adult or child voices } \\
\hline Adult voices & 23 & 47.9 \\
\hline Child voices & 9 & 18.8 \\
\hline \multicolumn{3}{|l|}{ Frequency of voice hearing } \\
\hline Once only & 8 & 16.7 \\
\hline A few times only & 8 & 16.7 \\
\hline Occasionally & 9 & 18.8 \\
\hline Regularly (up to twice a month) & 5 & 10.4 \\
\hline Once every $1-2$ months & 5 & 10.4 \\
\hline Frequently (2-3 times a week) & 5 & 10.4 \\
\hline Daily & 4 & 8.3 \\
\hline
\end{tabular}

${ }^{1}$ Due to variation in details reported about these phenomena, in some categories, percentages may not sum to 100 . Similarly, as some participants reported multiple voice-hearing phenomena or multiple attributions to different voices heard some percentages sum to greater than 100 .

her to come over and the experience stopped when friend arrived, that particular incident was very distressing $(1-10=9)$, when asked what she thought it was she said, "It could be my imagination running free".

\section{[F5]}

I thought I saw a red, tall blur; it was Satan, this year, 2-3 months ago, around Easter time (age 11). Just outside door looking at him. He didn't say anything "I don't think it was real". Seen Satan once, very briefly looked away and then looked back and it was gone or blinked and it was gone. I thought I saw Chucky standing there, just holding a knife, with a funny face (age 11). Attribution: thinks it's probably his imagination. Distress $=10$ petrified (Satan) 8/9
(Chucky) Impairment: Stayed up all night when he thought he saw Satan, too frightened to sleep. Fell asleep next day because so tried from night before (Satan). [M8]

Other explanations included the possibility that voices heard were of people who participants could not see or that their perceptual experiences were some form of sensory memory.

In the last few months, playing in the playground, heard a whispering voice, a mumbling sound, couldn't make out any words, one voice only, a couple of times (max of 3 times), was confused by this, looked around but there was no one talking, could have been people I couldn't see, wasn't worried by it because I knew it wasn't a ghost or anything. [M24]

Also hear the mumbling when someone is talking or when I'm alone. It's always coming from the direction of the hot press. Hear it every now and again 1-2 times a year, first heard it age 8. Attribution: It's memories crossing in my head. My memory can't find a place for it, it sounds familiar. [M14]

For many young people, their experiences evoked feelings of fear or worry even when they found a way to normalise them in some way:

Hears a mumbling voice in the attic. E.g., 'Let's go this way and see what they have'. First onset at 11 (in the last year). Occurs every time that she is left alone in the house by herself she hears it. Happens 3 times a week. She's not sure what it is, has talked to her friends about it and they also hear similar noises when they are at home by themselves so she thinks that this is perfectly normal. Distress 8/9. [F19]

\section{Sub-theme 2: Externalising}

Externalising was when participants attributed their experiences to an entity external to themselves. While entities included ghosts, the Devil, God and aliens, paranormal activity by ghosts was the most commonly reported externalising explanation in the sample. Paranormal beliefs were reported by over half of the sample but not all participants with paranormal beliefs attributed their UPTB experiences to the paranormal.

About two-in-five participants reported that some or all of their experiences could be explained by the existence of non-human, external forces. Of those, most referred to ghosts and spirits, including those of deceased relatives.

Girl speaks to her, even when no one else is there. Sometimes friends say they hear voice too but usually just L. Girl says 'hello'. Thinks it's a little girl with black hair, gothic looking. Hears different voices, 
all girls. Usually hears voices when alone, 1 voice at a time. She tries to ignore voice and sometimes they will go away. Thinks it's a ghost. Accepts that it could be her imagination when I 'throw her a line' (SIPS score $=5$ ) but thinks most likely a ghost. Voices have never conversed. Does not sound the same as our voices talking to her - different quality, raspy. Finds experiences frightening. [F1]

Sees faces in front of her speaking, look like faces of steam. Happens every time she wakes up in middle of night. Last week, woke up in middle of night, saw a few different faces squished together. They scream (not words, just a screaming sound). She closes her eyes and covers her ears. Loses sleep because of experiences; always tired now. Other hallucinations she thinks are dead people. Thought in the past that it might be her imagination but it kept happening so she no longer thinks it could be her imagination.... Didn't believe in Devil before but believes in him now and thinks he is sending ghosts to her. [F2]

Although paranormal interpretations were often accompanied by a willingness to consider a more rational explanation, for a small minority, the belief that external entities were the source of their perceptual experiences was absolute and held with conviction.

Whenever I get mad it makes pictures of 'you know who' appear-El Diablo. (first time age 10) It feels like I can hear something supernatural. It has 'horns and scars from top to bottom, hoofs, a lot of fur on its legs and waistline, it was red'. I see him from the corner of my eye and when I look over he's not there. I see him for about 5 minutes. It's very clear, not blurry. Terrified to look around 1-10=10 ... 'I felt something touching me on the shoulder, like a claw.' The longest time I seen him was for 20 mins ... Sometimes I might see him every day in the week. I try to dash sideways like in a zig-zag, run different ways to deceive him and bless myself. [M13]

Age 9, saw an alien head with arms coming out of its ears. Hears aliens/creatures/devil talking to him telling him he is god, they are experienced as being in a group of 3 or just one at a time, tell him he must save their world (a different world to Earth), they tell him he has a golden staff that he can use to kill their enemies, they tell him to destroy the Earth, to put a bomb in Earth's core.... He has also felt that the Devil controls him. Devil would make his hands feel stuck, says he cannot move his fingers when this happens .... When I asked if these experiences could be his imagination he said 'no', definitely thinks they are real aliens. [M4]
About one third of participants reported that their beliefs or experiences were shared by others and were therefore part of a collective sub-cultural belief system within their family or friendship networks.

Two years ago age 9. 5 minutes. Ghosts in castle in Donegal. Went at midnight. Could see ten figures or so. His dad with him but didn't see anything. Making screeching noises, 'Leave us alone' and 'Get out'. Ghosts-only explanation .... The next day and said all about it. His dad believed him because he thinks that [name of participant] can speak to ghosts.... His dad's aunt had 'this' as well. Thinks he has special powers. Three years old was in a relative's pub, and saw this girl and talked to her, not sure if it was a dream or not. Nobody else can remember it. Think it was his first time to see a ghost. [M31]

When going to jump a ditch age 11, heard the suggestion saying to 'run and jump' in the ditch. Said in the manner of 'there's an idea, you can do it if you want'. Sounds like an average person's voice-a whisper. Attribution: uncle (RIP). Tactile Hallucination: Feel tap on shoulder, a light touch, turned around and no one there. Attribution: Had an aura reading done age 11/12. She said that mum's brother (RIP) had latched onto my soul. It was a weird test. I think he's always there helping me-nice feeling not scary .... [From parent report] When [name of participant] was 2-3 years old, he seen a photo of mum's brother (RIP) and asked who it was-said he recognised him. [Name of participant] nearly died at birth. Mum excited that he said this. [M21]

It was unusual for participants to report having another person share any aspect of their UPTB experiences. In fact, only five participants reported shared experiences with their peers, providing them with a sub-cultural context for their own experiences.

Within last year Kilmainham Gaol [jail], heard mumbling sounds and chains rattling so think I heard 'get em out of here', sound sounded like a man, saw a pair of legs with chains on them saw the whole body but not very clearly, friend said she saw ghost too but didn't hear the voice, think it was a ghost but says it could also be her imagination. [F21]

\section{Sub-theme 3: Distancing}

Distancing was when UPTBs were not aligned to biomedical or psychiatric explanations. This distancing was observed as a latent theme in almost all cases, evidenced by the absence of any explicit reference to psychosis or other mental health difficulties in young people's explanations. There was no evidence that this process was conscious and distancing may therefore 
reflect a lack of awareness of psychiatric concepts such as hallucinations and delusions in this sample. There were just two cases where distancing was more explicit, with evidence that participants did not want to align their experiences to a psychiatric frame of reference. In one case, where a participant reported multiple, complex and vivid UPTBs across all domains, most of which were attributed to the Devil, he was noted to have said: 'Luckily I'm not schizophrenic disorder - causes you to see things' [M13]. In another case, a participant who reported an unexplained visual experience was recorded as saying he was 'worried at the time that he might be going crazy' [M10].

\section{Superordinate theme: uncertainty}

Although the three explanatory themes above have been presented separately, about two thirds of participants lacked certainty about their experiences. A small number proffered 'don't know' in response to questions about how they made sense of their experiences. However, for others, their efforts to make sense of their experiences were characterised by confusion and a lack of surety. This could result in tentative, multiple and/or competing explanations for their experiences, as evident in the data excerpts below.

Mainly happened at night when I was coming up the stairs, in the room, not in bed. Mainly because my Godmother died Xmas week 2 years ago. Week coming up to anniversary heard voice, thinks she's talking to me. Look around and no one's there, it only happens when I'm on my own. Could be my imagination. Distress: 2/3. No impairment. Attribution: imagination or aunt talking to me. [M15].

Start of last year heard a knock that sounded like her PGF's [paternal grandfather's] knock, father heard it too. When alone in room a couple of months ago, heard a strange mumbling sound like a voice lasted 3 or 4 mins, fear/worry-5/10, attribution: don't know, it could have been my imagination but it could have been something supernatural, more likely something supernatural, like a ghost. [F21]

\section{Discussion}

To our knowledge, this is the first study to report findings on the phenomenology of and explanations for UPTBs in a non-help-seeking, community sample of young people using qualitative clinical interview data. In line with the existing evidence (Freeman, 2006; Larøi, 2006; Van Os et al. 2009; Pugh et al. 2018), our findings demonstrate considerable variation in the frequency, intensity and characteristics of UPTBs across four phenomenological domains. Hearing voices was the most prevalent phenomenon reported, with evidence of a rich and diverse range of characteristics of voice hearing among those who reported these experiences. Additionally, we identified a number of themes relating to how young people made sense of their experiences, with uncertainty a dominant theme in young people's attempts to explain their experiences.

\section{The phenomenology of UPTBs}

Findings from this study have provided new evidence and insights into the phenomenological diversity of UPTBs among young adolescents in the general population. While voice hearing was the most prevalent UPTB reported, as has been found in adult clinical samples (Pienkos et al. 2019), perceptual phenomena reported in this study extended well beyond hearing voices and involved a range of sensory modalities. This supports existing evidence that UPTBs in children and adolescents can involve both UPEs and unusual thoughts and beliefs (Altman et al. 1997; Dhossche et al. 2002; Johns et al. 2004; Barragan et al. 2011; BartelsVelthuis et al. 2011; Sullivan et al. 2020). However, the finding that just one individual only reported unusual thoughts and beliefs suggests that most UPTBs in childhood and early adolescence will involve UPEs, which may or may not be accompanied by unusual thoughts and beliefs. Further qualitative studies are warranted to explore young people's UPTB experiences in greater depth and the meaning, if any, they ascribe to them.

\section{The phenomenology of voice hearing}

Compared to both clinical psychosis and non-clinical samples (Stephane et al. 2003; Larøi et al. 2012; McCarthy-Jones et al. 2014; Woods et al. 2015), participants in this study demonstrated similar phenomenological diversity in their voice-hearing experiences, from once-off experiences of low-level, benign mumbling to repeated experiences of clear and distinct voices, conversing or speaking in sentences. This finding supports the existing evidence that the phenomenological breadth of voice-hearing experiences is not exclusive to people with psychotic disorders (Nordgaard et al. 2008; Soares-Weiser et al. 2015; Cavelti et al. 2018). However, comparison of findings from our non-clinical sample with those from McCarthy-Jones et al.'s (2014) largely adult sample of 199 individuals with schizophrenia demonstrated clear phenomenological differences. In that study, $86 \%$ of individuals were categorised as having 'constant, commanding and commenting AVHs', whereas in our sample, commanding voices were reported by just $8.3 \%$ of individuals, commenting voices by $2.1 \%$ and no individual reported hearing voices constantly.

Daalman et al. (2011) compared voice-hearing adults with and without a psychotic disorder. They found that 
voices with a negative emotional valence predicted $88 \%$ of individuals who had a psychotic disorder. They also found that non-psychotic voice hearers had an earlier age of AVH onset and heard voices less frequently than those with psychotic disorders. This complements the findings from our non-psychotic sample of early adolescents, with few reporting malevolent voices and with most voice-hearing occurring infrequently. While evidence from this study supports a view that there are both phenomenological similarities and differences between voice hearing in individuals with and without psychotic disorder, longitudinal analysis of AVHs and other UPTB phenomena and outcomes are essential to advance an understanding of early phenomenological characteristics that may provide more reliable indicators of later risk of psychopathology and functioning deficits in young people with a history of UPTBs.

\section{Subjective explanations and interpretations of UPTBs}

The idea that subjectively embodied experiences are always experienced in the context of multiple and dynamic cultural contexts and meanings is well recognised in the field of anthropology (Larsen, 2004; Csordas, 2015). Findings on how young people interpreted and made sense of their experiences in this study complement this cultural anthropological perspective. Similar to Larsen's (2004) ethnographic study of how adults experiencing a first episode of psychosis made sense of their hallucinations and delusions, we found that most young people did try to make sense of or explain their experiences. Larsen proposed that explanations and interpretations for hallucinations and delusions can provide individuals with 'a means of controlling their disturbing sensations and experiences by objectifying them in language' (2004: 465). This social and cultural need to find acceptable explanations for experiences that fall outside of what are perceived to be normative human perceptions and beliefs can be applied to the sub-themes of normalising, externalising and distancing identified in this study. All three themes offered individuals a way to make sense of their experiences within a culturally acceptable and nonstigmatising frame of reference.

In the case of normalising, individuals found a safe and personally acceptable way to make sense of experiences by assigning them to fantasy, tricks of the mind, memory and vivid imagining. Externalising and the high levels of paranormal beliefs and attributions in this study can also be interpreted as means of providing a recognised sub-cultural context for young people's experiences, as has been reported elsewhere (Rabeyron $\&$ Loose, 2015). The adoption of such paranormal explanations and interpretations for unusual experiences can be viewed as serving the dual purpose of both grounding unusual experiences within a culturally acceptable frame of reference and avoiding the stigma associated with mental illness (Larøi et al. 2014). For example, in their paper, Larøi et al. (2014) cite multiple studies demonstrating that individuals who align their hallucinatory experiences to the supernatural often 'take considerable care to distinguish explicitly between the hallucinations of madness and hallucinations that indicate contact with the spiritual world'. Thus, from a cultural anthropological perspective, the paranormal beliefs and attributions found in this study may have offered individuals a 'cultural buffer', providing an acceptable cultural space to make sense of what might otherwise be unexplainable phenomena (Rabeyron \& Loose, 2015). Similarly, distancing, ensured that experiences were not aligned to potentially stigmatising psychiatric interpretations of UPTBs, a finding that contrasts with Larsen's (2004) study, where psychiatric explanations were embraced and valued by some individuals with psychosis as a way of making sense of their experiences. However, the age of individuals in the current study could be a factor in the absence of psychiatric explanations among most participants, rather than reflecting any conscious rejection of a biomedical explanatory framework.

The finding of high levels of paranormal beliefs in this study is consistent with previous studies that have identified an association between paranormal beliefs and UPTBs (Yung et al. 2005; Cella et al. 2012; Unterrassner et al. 2017). Importantly, existing evidence suggests that paranormal beliefs and associated perceptual and sensory experiences are often not pathological expressions of underlying mental disorder or psychosis or a source of distress among individuals who report these experiences (Cella et al. 2012; Brett et al. 2015; Unterrassner et al. 2017). This finding complements existing longitudinal findings from a qualitative study of a sub-sample of individuals from the ABD study cohort, where a number of young people who had reported early experiences of UPTBs were functioning well and not experiencing psychopathology in early adulthood (Coughlan et al. 2019). It also strengthens an argument to consider the language used to describe and interpret UPTBs in young people and to develop a more clinically sensitive model of these experiences that takes the phenomenology, cultural and environmental context and any associated distress into account.

With evidence that self-report measures of hallucinatory and delusional experiences can yield relatively high rates of false negatives (Rimvall et al. 2018), the fact that our data were collected by psychologists and psychiatrists using in-depth clinical interviews is a strength of this study. However, it is important to note that, 
because clinical interviews were not audio-recorded, data for this study were in the form of documented interviewer notes. This limited the available data on how participants conceptualised, understood and were impacted by their UPTB experiences. For example, inconsistent data recording relating to distress, a factor known to be associated with later psychotic disorder (Sullivan et al. 2020), meant it was not possible to explore distress across the sample. Green (2019) has argued that assumptions about the factual nature of UPTB experiences mean that there is potential for experiential accounts to be contaminated by how these experiences are explored with individuals. In that context, questions about the descriptive accuracy of reported experiences remain, particularly given the young age range of the current sample.

The challenge in identifying studies with equivalent findings to compare with those in this study reflects the heterogeneity of research methods used to collect data on UPTBs and other anomalous experiences. This is particularly the case when so many studies rely on restricted screening questionnaires that cluster phenomenologically diverse experiences to create a singular category of experience. Findings from this study suggest that UPTBs in youth capture a breadth of experiences beyond that of hearing voices. We propose that a more nuanced understanding of the significance of different dimensions of early UPTB experiences may yield greater insights into how benign or clinically relevant differing phenomena may be, particularly in the context of high levels of paranormal beliefs underlying experiences, which have previously been found not to have strong associations with either psychopathology or impaired functioning. Thus, while the small sample size in this study means that it is descriptive in nature, we believe that studies like these are essential to enhance our understanding of these relatively common yet aetiologically complex phenomena and to aid the generation of new hypotheses for testing in larger samples. As has been suggested previously (Brett et al. 2015), we believe that future studies should consider examining combinations of phenomena rather than focusing only on individual phenomenological subtypes or replying on a simple binary categorisation (i.e. 'psychotic-like experiences' $v$. 'no psychotic-like experiences'). Additional research with more complex models of these phenomena may provide new and important insights into the risk profiles of early manifestations of UPTBs in individuals with UPTBs.

\section{Conflict of interests statement}

Helen Coughlan has no conflicts of interests to disclose. Colm Healy has no conflicts of interests to disclose. Niamh Humphries has no conflicts of interests to disclose. Mary Clarke has no conflicts of interests to disclose, Ian Kelleherhas no conflicts of interests to disclose. Mary Cannon has no conflicts of interests to disclose.

\section{Ethical standards statement}

The authors assert that all procedures contributing to this work comply with the ethical standards of the relevant national and institutional committee on human experimentation with the Helsinki Declaration of 1975 , as revised in 2008. Ethical approval was granted by the Research Ethics Committees of Beaumont Hospital Dublin and the Royal College of Surgeons in Ireland. Participants were compensated for their time with a gift voucher.

\section{Financial support statement}

This work was supported by the Health Research Board (H.C., HPF-2015-974), (M.Cl., HRA-2015), (M. Ca., HRA-2015), (N.H., EIA-2017); and the European Research Council (C.H., grant number 724809), (M.Ca., grant number 724809).

\section{Supplementary material}

To view supplementary material for this article, please visit https:/ /doi.org/10.1017/ipm.2020.26

\section{References}

Al-Issa I (2018). The illusion of reality or the reality of illusion: hallucinations and culture. British Journal of Psychiatry 166, 368-373.

Altman H, Collins M, Mundy P (1997). Subclinical hallucinations and delusions in nonpsychotic adolescents. Journal of Child Psychology and Psychiatry 38, 413-420.

Assarroudi A, Heshmati Nabavi F, Armat MR, Ebadi A, Vaismoradi M (2018). Directed qualitative content analysis: the description and elaboration of its underpinning methods and data analysis process. Journal of Research in Nursing 23, 42-55.

Barragan M, Laurens KR, Navarro JB, Obiols JE (2011). Psychotic-like experiences and depressive symptoms in a community sample of adolescents. European Psychiatry 26, 396-401.

Bartels-Velthuis AA, van de Willige G, Jenner JA, Wiersma D, van Os J (2011). Auditory hallucinations in childhood: associations with adversity and delusional ideation. Psychological Medicine 42, 583-593.

Beavan V, Read J, Cartwright C (2011). The prevalence of voice-hearers in the general population: a literature review. Journal of Mental Health 20, 281-292.

Bentall RP (2004). Madness Explained: Psychosis and Human Nature. London: Penguin UK.

Braun V, Clarke V (2006). Using thematic analysis in psychology. Qualitative Research in Psychology 3, 77-101. 
Brendel DH (2006). Healing Psychiatry. Cambridge MA: MIT Press.

Brett CMC, Peters ER, McGuire PK (2015). Which psychotic experiences are associated with a need for clinical care? European Psychiatry 30, 648-654.

Calkins ME, Moore TM, Satterthwaite TD, Wolf DH, Turetsky BI, Roalf DR, Merikangas KR, Ruparel K, Kohler CG, Gur RC (2017). Persistence of psychosis spectrum symptoms in the Philadelphia neurodevelopmental cohort: a prospective two-year follow-up. World Psychiatry 16, 62-76.

Cavelti M, Thompson KN, Hulbert C, Betts J, Jackson H, Francey S, Homan P, Chanen AM (2018). Exploratory comparison of auditory verbal hallucinations and other psychotic symptoms among youth with borderline personality disorder or schizophrenia spectrum disorder. Early Intervention in Psychiatry 13, 1252-1262.

Cella M, Vellante M, Preti A (2012). How psychotic-like are paranormal beliefs? Journal of Behavior Therapy and Experimental Psychiatry 43, 897-900.

Corrigan PW, Kleinlein P (2005). The impact of mental illness stigma. In On the Stigma of Mental Illness: Practical Strategies for Research and Social Change (ed. P. W. Corrigan). Washington DC: American Psychological Association.

Corstens D, Longden E, McCarthy-Jones S, Waddingham R, Thomas N (2014). Emerging perspectives from the hearing voices movement: implications for research and practice. Schizophrenia Bulletin 40, S285-S294.

Coughlan H, Healy C, Ní Sheaghdha Á, Murray G, Humphries N, Clarke M, Cannon M (2019). Early risk and protective factors and young adult outcomes in a longitudinal sample of young people with a history of psychotic-like experiences. Early Intervention in Psychiatry. doi: 10.1111/eip.12855

Coughlan H, Tiedt L, Clarke M, Kelleher I, Tabish J, Molloy C, Harley M, Cannon M (2014). Prevalence of DSM-IV mental disorders, deliberate self-harm and suicidal ideation in early adolescence: an Irish populationbased study. Journal of Adolescence 37, 1-9.

Creswell JW (2012). Qualitative Inquiry and Research Design: Choosing Among Five Approaches, 3rd Edition. Los Angeles: Sage Publications.

Csordas TJ (2015). Cultural phenomenology and psychiatric illness. In Revisioning Psychiatry: Cultural Phenomenology, Critical Neuroscience, and Global Mental Health (eds. LJ Kirmayer, R Lemelson, CA Cummings). New York: Cambridge University Press.

Daalman K, Boks MP, Diederen KM, de Weijer AD, Blom JD, Kahn RS, Sommer IE (2011). The same or different? A phenomenological comparison of auditory verbal hallucinations in healthy and psychotic individuals. Journal of Clinical Psychiatry 72, 320-325.

Despert JL (1948). Delusional and hallucinatory experiences in children. American Journal of Psychiatry 104, 528-537.

Dhossche D, Ferdinand R, Van Der Ende J, Hofstra MB, Verhulst F (2002). Diagnostic outcome of self-reported hallucinations in a community sample of adolescents. Psychological Medicine 32, 619-627.
Freeman D (2006). Delusions in the nonclinical population. Current Psychiatry Reports 8, 191-204.

Garety PA, Kuipers E, Fowler D, Freeman D, Bebbington P (2001). A cognitive model of the positive symptoms of psychosis. Psychological Medicine 31, 189-195.

Goodman R (1997). The strengths and difficulties questionnaire: a research note. Journal of Child Psychology and Psychiatry 38, 581-586.

Green H (2019). Making up symptoms: psychic indeterminacy and the construction of psychotic phenomena. BJPsych Bulletin 43, 81-84.

Harland R, Morgan C, Hutchinson G (2004). Phenomenology, science and the anthropology of the self: a new model for the aetiology of psychosis. The British Journal of Psychiatry 185, 361-362.

Healy C, Campbell D, Coughlan H, Clarke M, Kelleher I, Cannon M (2018)a. Childhood psychotic experiences are associated with poorer global functioning throughout adolescence and into early adulthood. Acta Psychiatrica Scandinavica 138, 26-34.

Healy C, Gordon AA, Coughlan H, Clarke M, Kelleher I, Cannon M (2018)b. Do childhood psychotic experiences improve the prediction of adolescent psychopathology? A longitudinal population-based study. Early Intervention in Psychiatry 13, 1245-1251.

Hsieh H-F, Shannon SE (2005). Three approaches to qualitative content analysis. Qualitative Health Research 15, 1277-1288.

Humpston CS (2014). Perplexity and meaning: toward a phenomenological "core" of psychotic experiences. Schizophrenia Bulletin 40, 240-243.

Johns LC, Cannon M, Singleton N, Murray RM, Farrell M, Brugha T, Bebbington P, Jenkins R, Meltzer H (2004). Prevalence and correlates of self-reported psychotic symptoms in the British population. British Journal of Psychiatry 185, 298-305.

Kaufman J, Birmaher B, Brent D, Rao U, Flynn C, Moreci P, Williamson D, Ryan N (1997). Schedule for affective disorders and schizophrenia for school-age children-present and lifetime version (K-SADS-PL): initial reliability and validity data. Journal of the American Academy of Child and Adolescent Psychiatry 36, 980-988.

Kelleher I, Connor D, Clarke MC, Devlin N, Harley M, Cannon M (2012)a. Prevalence of psychotic symptoms in childhood and adolescence: a systematic review and meta-analysis of population-based studies. Psychological Medicine 42, 1857-1863.

Kelleher I, Harley M, Murtagh A, Cannon M (2011). Are screening instruments valid for psychotic-like experiences? A validation study of screening questions for psychotic-like experiences using in-depth clinical interview. Schizophrenia Bulletin 37, 362-369.

Kelleher I, Keeley H, Corcoran P, Lynch F, Fitzpatrick C, Devlin N, Molloy C, Roddy S, Clarke MC, Harley M, Arseneault L, Wasserman C, Carli V, Sarchiapone M, Hoven C, Wasserman D, Cannon M (2012)b. Clinicopathological significance of psychotic experiences in non-psychotic young people: evidence from four 
population-based studies. British Journal of Psychiatry 201, 26-32.

Kelleher I, Murtagh A, Molloy C, Roddy S, Clarke MC, Harley M, Cannon M (2012)c. Identification and characterization of prodromal risk syndromes in young adolescents in the community: a population-based clinical interview study. Schizophrenia Bulletin 38, 239-46.

Krippendorff K (2004). Content Analysis: An Introduction to its Methodology. California: Sage Publications.

Kvale S (1996). Interviews. An Introduction to Qualitative Research Writing. Thousand Oaks, CA: Sage Publications.

Larøi F (2006). The phenomenological diversity of hallucinations: some theoretical and clinical implications. Psychologica Belgica 46, 1-2.

Larøi F, Luhrmann TM, Bell V, Christian WA, Jr, Deshpande S, Fernyhough C, Jenkins J, Woods A (2014). Culture and hallucinations: overview and future directions. Schizophrenia Bulletin 40, S213-S220.

Larøi F, Sommer IE, Blom JD, Fernyhough C, Ffytche DH, Hugdahl K, Johns LC, McCarthy-Jones S, Preti A, Raballo A (2012). The characteristic features of auditory verbal hallucinations in clinical and nonclinical groups: state-of-the-art overview and future directions. Schizophrenia Bulletin 38, 724-733.

Larsen JA (2004). Finding meaning in first episode psychosis: experience, agency, and the cultural repertoire. Medical Anthropology Quarterly 18, 447-471.

Longden E, Madill A, Waterman MG (2012). Dissociation, trauma, and the role of lived experience: toward a new conceptualization of voice hearing. Psychological Bulletin 138, 28.

Martindale B, Summers A (2013). The psychodynamics of psychosis. Advances in Psychiatric Treatment 19, 124-131.

Mayring P (2004). Qualitative content analysis. A Companion to Qualitative Research 1, 159-176.

McCarthy-Jones S, Trauer T, Mackinnon A, Sims E, Thomas N, Copolov DL (2014). A new phenomenological survey of auditory hallucinations: evidence for subtypes and implications for theory and practice. Schizophrenia Bulletin 40, 231-235.

Meyer A (1908). What do histories of cases of insanity teach us concerning preventive mental hygiene during the years of school life? The Psychological Clinic 2, 89.

Nordgaard J, Arnfred SM, Handest P, Parnas J (2008). The diagnostic status of first-rank symptoms. Schizophrenia Bulletin 34, 137-154.

Oyebode F (2015). Sims' Symptoms in the Mind: Textbook of Descriptive Psychopathology. Edinburgh: Saunders/Elsevier.

Pienkos E, Giersch A, Hansen M, Humpston C, McCarthy-Jones S, Mishara A, Nelson B, Park S, Raballo A, Sharma R (2019). Hallucinations beyond voices: a conceptual review of the phenomenology of altered perception in psychosis. Schizophrenia Bulletin 45, S67-S77.

Pugh K, Luzon O, Ellett L (2018). Responsibility beliefs and persecutory delusions. Psychiatry Research 259, 340-344.

Rabeyron T, Loose T (2015). Anomalous experiences, trauma, and symbolization processes at the frontiers between psychoanalysis and cognitive neurosciences. Frontiers in Psychology 6, 1926-1926.

Rabeyron T, Watt C (2010). Paranormal experiences, mental health and mental boundaries, and psi. Personality and Individual Differences 48, 487-492.

Rimvall MK, Gundersen S, Clemmensen L, Munkholm A, Larsen JT, Skovgaard AM, Rask CU, Verhulst F, van Os J, Jeppesen P (2018). Evidence that self-reported psychotic experiences in children are clinically relevant. Schizophrenia Research 204, 415.

Soares-Weiser K, Maayan N, Bergman H, Davenport C, Kirkham AJ, Grabowski S, Adams CE (2015). First rank symptoms for schizophrenia. Cochrane Database of Systematic Reviews.

Stephane M, Thuras P, Nasrallah H, Georgopoulos AP (2003). The internal structure of the phenomenology of auditory verbal hallucinations. Schizophrenia Research 61, 185-193.

Stochl J, Khandaker G, Lewis G, Perez J, Goodyer I, Zammit S, Sullivan S, Croudace T, Jones P (2015). Mood, anxiety and psychotic phenomena measure a common psychopathological factor. Psychological Medicine 45, 1483-1493.

Sullivan SA, Kounali D, Cannon M, David AS, Fletcher PC, Holmans P, Jones H, Jones PB, Linden DE, Lewis G (2020). A population-based cohort study examining the incidence and impact of psychotic experiences from childhood to adulthood, and prediction of psychotic disorder. American Journal of Psychiatry appi. ajp. 2019.19060654.

Taylor CDJ, Harper SF (2016). Early maladaptive schema, social functioning and distress in psychosis: a preliminary investigation. Clinical Psychologist 21, 135-142.

Unterrassner L, Wyss TA, Wotruba D, Haker H, Rössler W (2017). The intricate relationship between psychotic-like experiences and associated subclinical symptoms in healthy individuals. Frontiers in Psychology 8, 1537.

Upthegrove R, Broome M, Caldwell K, Ives J, Oyebode F, Wood S (2016). Understanding auditory verbal hallucinations: a systematic review of current evidence. Acta Psychiatrica Scandinavica 133, 352-367.

Van Os J, Linscott RJ, Myin-Germeys I, Delespaul P, Krabbendam L (2009). A systematic review and meta-analysis of the psychosis continuum: evidence for a psychosis proneness-persistence-impairment model of psychotic disorder. Psychological Medicine 39, 179-195.

Woods A, Jones N, Alderson-Day B, Callard F, Fernyhough C (2015). Experiences of hearing voices: analysis of a novel phenomenological survey. Lancet Psychiatry 2, 323-331.

Yung AR, Buckby JA, Cotton SM, Cosgrave EM, Killackey EJ, Stanford C, Godfrey K, McGorry PD (2005). Psychotic-like experiences in nonpsychotic helpseekers: associations with distress, depression, and disability. Schizophrenia Bulletin 32, 352-359. 